\title{
Daytime twin-peak structures observed at southern African and European middle latitudes on 8-13 April 2012
}

\author{
Zama T. Katamzi ${ }^{1,2}$, John Bosco Habarulema ${ }^{1,2}$, and Nigussie M. Giday ${ }^{1,2}$ \\ ${ }^{1}$ South African National Space Agency (SANSA), Space Science, Hermanus, Western Cape, South Africa \\ ${ }^{2}$ Department of Physics and Electronics, Rhodes University, Grahamstown, Eastern Cape, South Africa \\ Correspondence to: Zama T. Katamzi (zkatamzi@sansa.org.za)
}

Received: 14 December 2015 - Revised: 2 June 2016 - Accepted: 7 June 2016 - Published: 12 July 2016

\begin{abstract}
Daytime twin-peak structures, also known as biteout or diurnal double-maxima structures, are ionospheric phenomena in which the diurnal ionospheric trend shows two peaks (instead of the normal one) during the daytime. This study reports on first simultaneous observations of these structures in the Global Positioning System and ionosonde measurements from the southern African and European middle-latitude stations during a mostly quiet geomagnetic condition period of 8-13 April 2012, which indicates that their occurrence and therefore driving mechanism(s) may not be localised. It is found that the daytime twin-peak structures generally appear later in the Northern Hemisphere with a $1-3 \mathrm{~h}$ latency although they propagate mostly equatorward in both hemispheres. Proxies of meridional neutral winds were calculated from available manually scaled ionosonde measurements and used to explore their potential as drivers of the structures. Bite-out events were linked to downward drifts of the vertical component of equivalent neutral winds causing plasma depletions. In addition, evidence of sporadic E layers at the same time as enhancements of daytime twin-peak structures suggests that the tides had influence via the meridional wind shear in generating these structures through the dynamo electric field which resulted in upward $\mathbf{E} \times \mathbf{B}$ drifts.
\end{abstract}

Keywords. Ionosphere (ionosphere-atmosphere interactions; ionospheric disturbances; mid-latitude ionosphere)

\section{Introduction}

Daytime twin-peak structures, also known as bite-out or diurnal double-maxima (DDM) structures, are ionospheric phenomena in which the diurnal ionospheric trend shows two peaks (instead of the normal one) during the daytime due to an anomalous daytime depression or irregular enhancement of the maximum critical frequency of the $\mathrm{F} 2$ region $(f o \mathrm{~F} 2)$, electron density or total electron content (TEC). Observations of the bite-outs at different latitudes have been largely reported as early as the 1960s. Huang and Jeng (1978) observed bite-outs over Chung-li (China) during both quiet and disturbed geomagnetic conditions and found that these structures had a tendency to occur on the first storm day. They also observed that the bite-outs had a higher occurrence rate during solstices than during equinoxes. Khan et al. (1985) reported on bite-outs observed over Pakistan (middle latitude) for a year (1982-1983) and found that the bite-outs travelling from high latitude to lower latitude (i.e. equatorward) were abundant in winter, while those travelling from lower to higher latitudes (i.e. poleward) were abundant in summer. Saryo et al. (1989) reported first observation of a midday bite-out event over Japan on 12 November 1985 from electron density profiles obtained from MU (Middle and Upper atmosphere) radar and several ionosonde stations. Their biteout event was moving from higher- to lower-latitude stations (i.e. equatorward). Katamzi et al. (2012) studied DDMs over the middle-latitude station in Italy over more than one solar cycle (i.e. 1975-1991) and found a $22 \%$ occurrence rate throughout the period. They also found that DDMs are more likely to be observed during solstices than during equinoxes, but unlike previous studies they found that the DDMs were independent of geomagnetic activity influence as they are as likely to occur during disturbed as during quiet geomagnetic conditions. Generally vertical plasma drifts due to either electromagnetic forces, meridional neutral winds, changes in chemical composition or a combination of these are thought to be responsible for the $f o \mathrm{~F} 2$ or electron density or TEC in- 
crease (e.g. DDM) or decrease (e.g. bite-out) seen in these daytime twin-peak structures. The vertical plasma drifts arise through the action of the zonal electric field and/or thermospheric meridional winds due to geomagnetic field-aligned motion of ion drag. Past studies such as Kohl et al. (1968), Khan et al. (1985) and Pi et al. (1993) have argued that at middle latitudes, especially during quiet conditions, meridional neutral winds dominate, while during storms and substorms prompt penetrating electric fields may increase the role of the zonal electric fields in uplifting or depressing the ionosphere. Using the ionospheric continuity equation and the equation of motion of the neutral atmosphere, Kohl et al. (1968) showed that the diurnal variation of the neutral winds can explain the bite-out structure; the horizontal neutral wind moves the F-region plasma along the magnetic field lines, and the vertical component of this wind produces vertical movements of this region. The bite-out is then the result of a downward movement/drift which moves the F-region plasma into a region of greater loss rate (i.e. higher dissociative recombination rate of oxygen ions). Also, a study of DDMs at middle and lower latitudes of North America and Europe related to substorm events by Pi et al. (1993) demonstrated that at lower latitudes the enhancements of DDMs were the result of prompt penetrating electric fields during substorms through the upward vertical $\mathbf{E} \times \mathbf{B}$ drift movement, while the bite-outs were caused by chemical loss at F-region altitudes.

Recently, Lynn et al. (2014) reported on midday bite-out structures observed using $f o \mathrm{~F} 2$ measurements from several ionosondes in Australia during the April equinoxes in solar minimum (2007-2008) and solar maximum (2011-2013). They also suggested the meridional winds as a driver but added that tidal activity might also have an influence as they observed simultaneous occurrence of descending sporadic E (Es) layers with these structures. Tides are atmospheric oscillations in the atmosphere that are excited by variations of absorption of solar radiation and Sun-Moon gravitational forces. They have periods that are integral fractions of a solar (or lunar) day; for instance solar tides have diurnal, semidiurnal and terdiurnal components (i.e. periods of 24,12 and $8 \mathrm{~h}$ respectively). The components of the tides that propagate with the apparent motion of the Sun relative to the surface of the Earth (i.e. Sun-synchronous westward propagating) are called migrating tides, and those that are non-Sun-synchronous are called non-migrating tides. Atmospheric tides originate from the troposphere and stratosphere and propagate upwards to the thermosphere, where they typically reach their maximum amplitudes and then dissipate, thus transferring energy and modifying the basic wind circulation in this region. There have been many studies that show that the behaviour of the winds exhibit the presence of tidal components and that these components modulate the mean zonal and meridional winds (e.g. Amayenc , 1974; Burrage et al., 1995; Hibbins et al., 2011; Jones et al., 2014; Xiong et al., 2015, and references therein). Many studies have reported evidence of non-migrating tides propagating and cou- pling into the ionosphere through various processes and features. For example, evidence from models and satellite measurements suggest that the summer night-time electron density anomalous enhancements at middle latitudes are generated through a non-migrating diurnal tide modifying vertical neutral wind drifts (Xiong et al., 2015). In addition, the dynamo electric field in the $\mathrm{E}$ region which modulates the electron density at the equatorial, low and middle latitudes is proposed to be created by interaction of the tides with the E region (Forbes et al., 2008; Zhang et al, 2010). Also, Jones et al. (2014) showed that tidal dissipation leads to changes in the meridional winds that produce field-aligned plasma motion which affects the $\mathrm{F} 2$ region peak height ( $h m \mathrm{~F} 2)$.

The vertical wind shear theory of Whitehead (1961) is generally used in order to understand the cause and effect of the tides and the ionospheric $\mathrm{E}$ region dynamo. In this theory it was shown that horizontal wind shear, mainly generated as solar tides propagate upwards, leads to the formation of Es layers through an interaction between the Earth's magnetic field and the ions (Fytterer et al., 2014). This is because nonmigrating tides at low and middle latitudes modify the general wind circulation and can cause partially ionised plasma to move across the Earth's magnetic field lines while the electrons remain fixed to the magnetic field because of their large gyro frequency / collision frequency ratio, which results in an electromotive force with ensuing electric currents and dynamo electric fields (Oberheide et al., 2015). According to this theory, the dynamo electric fields result through the $\mathbf{v} \times \mathbf{B}$ motions, where $\mathbf{v}$ is the horizontal wind (i.e. zonal and meridional) and $\mathbf{B}$ is the magnetic field. In the presence of the magnetic field the dynamo electric field results in vertical plasma drift, where ions converge into thin and dense plasma layers known as Es layers. Tide-like structures, especially diurnal and semidiurnal tidal components, have been observed in downward-propagating Es layers, confirming that thermal tides are the primary source of wind shear (Haldoupis et al., 2006; Arras et al., 2009; Fytterer et al., 2014). It is also important to note that the E-region dynamo electric field reaches into the $\mathrm{F}$ region via the magnetic field lines, where they drive vertical and horizontal plasma drifts.

This paper will present results on the dynamics of twinpeak structures simultaneously observed at middle latitudes in southern Africa and Europe for the mostly quiet geomagnetic condition period of 8-12 April 2012 and weak geomagnetic storm on 13 April 2012. This is the first study which looks at the characteristics of daytime twin peaks simultaneously occurring at the middle latitudes of the Northern and Southern Hemisphere in an attempt to understand the dynamics that generate and drive them. In an effort to find possible drivers of these structures, ionosonde measurements are used to support the TEC measurements. 
Table 1. Geographic and geomagnetic coordinates of GPS and ionosonde stations. Note: north/east positive and south/west negative and geomagnetic coordinates at $300 \mathrm{~km}$ altitude.

\begin{tabular}{|c|c|c|c|c|c|c|}
\hline Station code & Name (country) & $\begin{array}{r}\text { Geographic } \\
\text { latitude }\end{array}$ & $\begin{array}{r}\text { Geographic } \\
\text { longitude }\end{array}$ & $\begin{array}{r}\text { Geomagnetic } \\
\text { latitude }\end{array}$ & $\begin{array}{r}\text { Geomagnetic } \\
\text { longitude }\end{array}$ & Local time \\
\hline \multicolumn{7}{|c|}{ GPS stations along $30^{\circ} \mathrm{E}$} \\
\hline PRET & Pretoria (South Africa) & -25.73 & 28.28 & -35.03 & 96.70 & $\mathrm{UT}+1.9 \mathrm{~h}$ \\
\hline TDOU & Thohoyandou (South Africa) & -23.08 & 30.38 & -32.61 & 99.71 & $\mathrm{UT}+2.0 \mathrm{~h}$ \\
\hline ZAMB & Lusaka (Zambia) & -15.43 & 28.31 & -28.10 & 98.24 & $\mathrm{UT}+1.9 \mathrm{~h}$ \\
\hline TUBI & Gebze (Turkey) & 40.79 & 29.45 & 35.46 & 102.42 & $\mathrm{UT}+2.0 \mathrm{~h}$ \\
\hline MIKL & Mykolaiv (Ukraine) & 46.97 & 31.97 & 42.47 & 105.58 & $\mathrm{UT}+2.1 \mathrm{~h}$ \\
\hline GLSV & Kiev (Ukraine) & 50.36 & 30.50 & 46.13 & 104.77 & $\mathrm{UT}+2.0 \mathrm{~h}$ \\
\hline \multicolumn{7}{|c|}{ GPS stations along $18^{\circ} \mathrm{E}$} \\
\hline HNUS & Hermanus (South Africa) & -34.42 & 19.22 & -41.78 & 83.89 & $\mathrm{UT}+1.3 \mathrm{~h}$ \\
\hline LGBN & Langebaan (South Africa) & -32.97 & 18.16 & -40.69 & 83.47 & $\mathrm{UT}+1.2 \mathrm{~h}$ \\
\hline SBOK & Springbok (South Africa) & -29.67 & 18.88 & -38.24 & 85.61 & $\mathrm{UT}+1.3 \mathrm{~h}$ \\
\hline PENC & Penc (Hungary) & 47.79 & 19.28 & 43.06 & 94.01 & $\mathrm{UT}+1.3 \mathrm{~h}$ \\
\hline WROC & Wroclaw (Poland) & 51.11 & 17.07 & 46.86 & 92.79 & $\mathrm{UT}+1.1 \mathrm{~h}$ \\
\hline \multicolumn{7}{|c|}{ GPS stations within the EIA region } \\
\hline GETA & Geita (Tanzania) & -2.88 & 32.22 & -17.53 & 103.65 & $\mathrm{UT}+2.1 \mathrm{~h}$ \\
\hline EBBE & Entebbe (Uganda) & 0.04 & 32.44 & -15.76 & 103.98 & $\mathrm{UT}+2.2 \mathrm{~h}$ \\
\hline MOIU & Eldoret (Kenya) & 0.29 & 35.29 & -15.64 & 106.89 & $\mathrm{UT}+2.4 \mathrm{~h}$ \\
\hline \multicolumn{7}{|c|}{ Ionosonde stations } \\
\hline MU12K & Madimbo (South Africa) & -22.40 & 30.90 & -31.96 & 100.44 & $\mathrm{UT}+2.1 \mathrm{~h}$ \\
\hline HE13N & Hermanus (South Africa) & -34.42 & 19.22 & -41.78 & 83.89 & $\mathrm{UT}+1.3 \mathrm{~h}$ \\
\hline PQ052 & Pruhonice (Czech Republic) & 50.00 & 14.60 & 45.59 & 90.36 & $\mathrm{UT}+1.0 \mathrm{~h}$ \\
\hline
\end{tabular}

\section{Data and method}

Since the Global Navigational Satellite System (GNSS) has a wide global coverage and readily available data, TEC measurements from the International GNSS Service (IGS) and South Africa's Trignet networks for several GNSS stations at the middle latitudes in southern Africa and Europe are used to obtain dynamical information of the daytime twin-peak structures. These TEC measurements were derived from dual-frequency Global Positioning System (GPS) observations using a GPS-TEC software developed at Boston College. This software uses code and phase values for $\mathrm{L} 1$ and $\mathrm{L} 2$ frequencies (i.e. $f 1=1575.42 \mathrm{MHz}$ and $f 2=1227.60 \mathrm{MHz}$ ) to eliminate effects of differential clock errors in its calculation of slant TEC. Differential satellite biases published by the University of Bern and receiver biases calculated by minimising the TEC variability between 02:00 and 06:00 LT (local time) are also used by the software in order to give absolute TEC measurements (Seemala and Valladares, 2011). Vertical TEC is then derived from the slant TEC value assuming a thin shell ionosphere at $350 \mathrm{~km}$. In this study, vertical TEC values measured in TECU $\left(10^{16}\right.$ electrons $\left.\mathrm{m}^{-2}\right)$ were calculated from satellites above $30^{\circ}$ elevation at $30 \mathrm{~s}$ intervals. For GPS stations with a co- located or closely located ionosonde station, maximum electron density and maximum heights of the $\mathrm{F} 2$ region $(N m \mathrm{~F} 2$ and $h m \mathrm{~F} 2$ respectively) were also obtained from manually scaled ionosonde data at $15 \mathrm{~min}$ intervals. Table 1 presents the geographic and geomagnetic coordinates of the GPS and ionosonde stations used in this study as well as their respective local time, while Fig. 1 shows the distribution of these instruments on a map.

In order to explore meridional winds as possible driving mechanisms for the observed daytime twin peaks, and since there are no direct measurements of neutral winds available over the region of interest, vertical drifts due to equivalent meridional winds were estimated from ionosonde measurements as previously done by Miller et al. (1986), Dyson et al. (1997), Liu et al. (2004) and Maruyama et al. (2008). Manually scaled $N m \mathrm{~F} 2$ and $h m \mathrm{~F} 2$ measurements from Hermanus $\left(34.42^{\circ} \mathrm{S}, 19.22^{\circ} \mathrm{E}\right)$, Madimbo $\left(22.40^{\circ} \mathrm{S}, 30.90^{\circ} \mathrm{E}\right)$ and Pruhonice $\left(50.00^{\circ} \mathrm{N}, 14.60^{\circ} \mathrm{E}\right)$ ionosonde stations were used as inputs in a method developed by Liu et al. (2003). The method also uses ion, electron and neutral temperatures as inputs, which were obtained from the International Reference Ionosphere (IRI-2012) model (Bilitza et al., 2014), as well as $\mathrm{O}, \mathrm{O}_{2}$ and $\mathrm{N}_{2}$ concentrations, which were obtained from the Mass Spectrometer and Incoherent Scatter Radar 


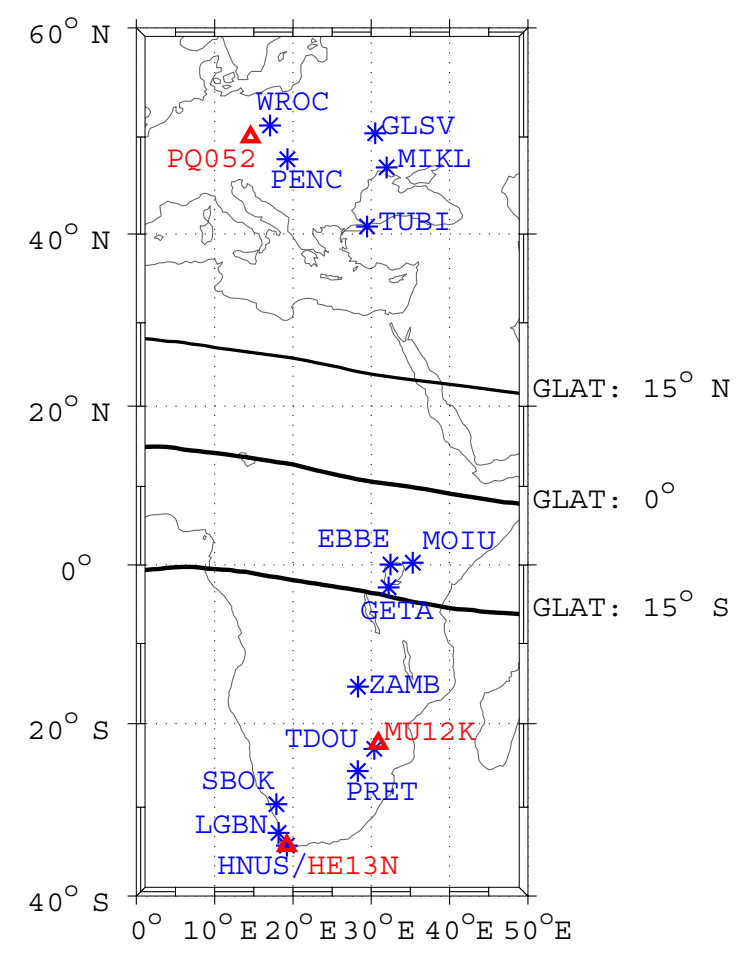

Figure 1. Map showing the locations of GPS (blue $*$ ) and ionosonde (red $\triangle$ ) stations used for this study.

(MSIS-90) model (Hedin, 1991). The magnetic dip angles at Hermanus, Madimbo and Pruhonice were roughly -64.17 , -57.76 and $65.93^{\circ}$ respectively. It is important to note that the Liu et al. (2003) technique derives the vertical component of the equivalent meridional winds, which is a combination of the contribution from the horizontal neutral meridional winds and the vertical $\mathbf{E} \times \mathbf{B}$ drifts on the ionospheric plasma movement. To obtain true meridional winds, the contributions from the $\mathbf{E} \times \mathbf{B}$ drifts should be removed. However at middle latitudes during quiet conditions, as demonstrated by the disturbance storm time (Dst) index on 8 to 12 April 2012 in Fig. 2, the $\mathbf{E} \times \mathbf{B}$ drifts should be insignificant in the dynamical processes that drive ionospheric plasma movements.

\section{Results}

Strong daytime twin-peak structures were observed in diurnal TEC measurements for the period 8-13 April 2012 for GPS stations in the middle-latitude regions in southern Africa and Europe along the 30 and $18^{\circ} \mathrm{E}$ longitudes as shown in Fig. 3. The period during which the twin-peak structures are observed is mostly geomagnetically quiet except for 13 April when Dst reached $-49 \mathrm{nT}$ at 04:00 UT, indicating an occurrence of a weak geomagnetic storm; refer to Fig. 2. These structures are seen by all GPS stations on 11 and 12 April, but only by some stations on the other days.

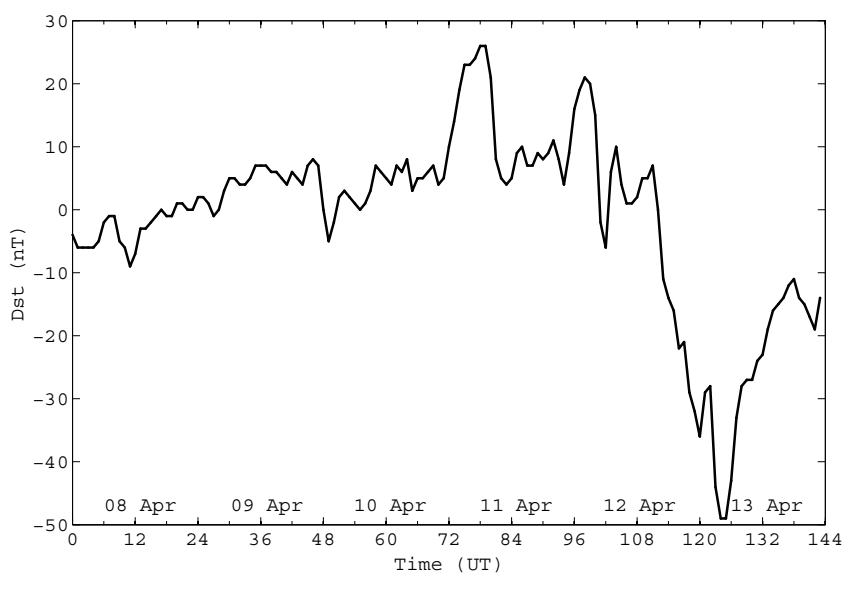

Figure 2. Storm time index Dst for the period of 8 to 13 April 2012.

In the Southern Hemisphere (i.e. southern Africa) the twinpeak structure occurs as a bite-out, while in the Northern Hemisphere (i.e. Europe) it appears as a secondary afternoon peak/enhancement. Table 2 presents the time of occurrence of each peak and depletion of the structures and shows that in the Southern Hemisphere the first peak occurs before local noon, the depletion around local noon and the second peak in the afternoon. However in the Northern Hemisphere the first peak occurs around local noon or after noon, while the depletion and second peak occur in the late afternoon but before local sunset. The twin-peak structures are observed earlier in the Southern Hemisphere than in the Northern Hemisphere, by about $1-3 \mathrm{~h}$. The time difference could be due to a difference in solar zenith angle because of differences in seasons between the hemispheres (i.e. autumn in the south and spring in the north) and higher geographic latitudes of the GPS stations in the Northern Hemisphere. In addition, within each hemisphere the time of occurrence of the twin-peak structure is not consistent from day to day, having a time variance of about $1-2 \mathrm{~h}$.

In the Southern Hemisphere, the twin-peak structures seem to propagate mostly equatorward on 9, 10 and 12 April, while on 11 April the structure is seen to propagate mostly poleward at stations along the $30^{\circ} \mathrm{E}$ longitude but mostly equatorward at stations along $18^{\circ} \mathrm{E}$ longitude. In the Northern Hemisphere, the twin-peak structures seem to propagate mostly equatorward on 11 and 12 April except for stations along the $30^{\circ} \mathrm{E}$ longitude on 11 April when the structure is seen to propagate mostly poleward. The fact that the most frequent propagation direction of the structures observed here is towards the Equator (i.e. about $64 \%$ ) suggests that the equatorial ionisation anomaly (EIA) plays no direct role in the generation of the observed twin-peak structures. To test this, we looked for GPS stations within the EIA region as well as our longitude range and found three stations (i.e. EBBE, GETA and MOIU) within the southern crest of the EIA that had data during the period of interest (i.e. 8- 


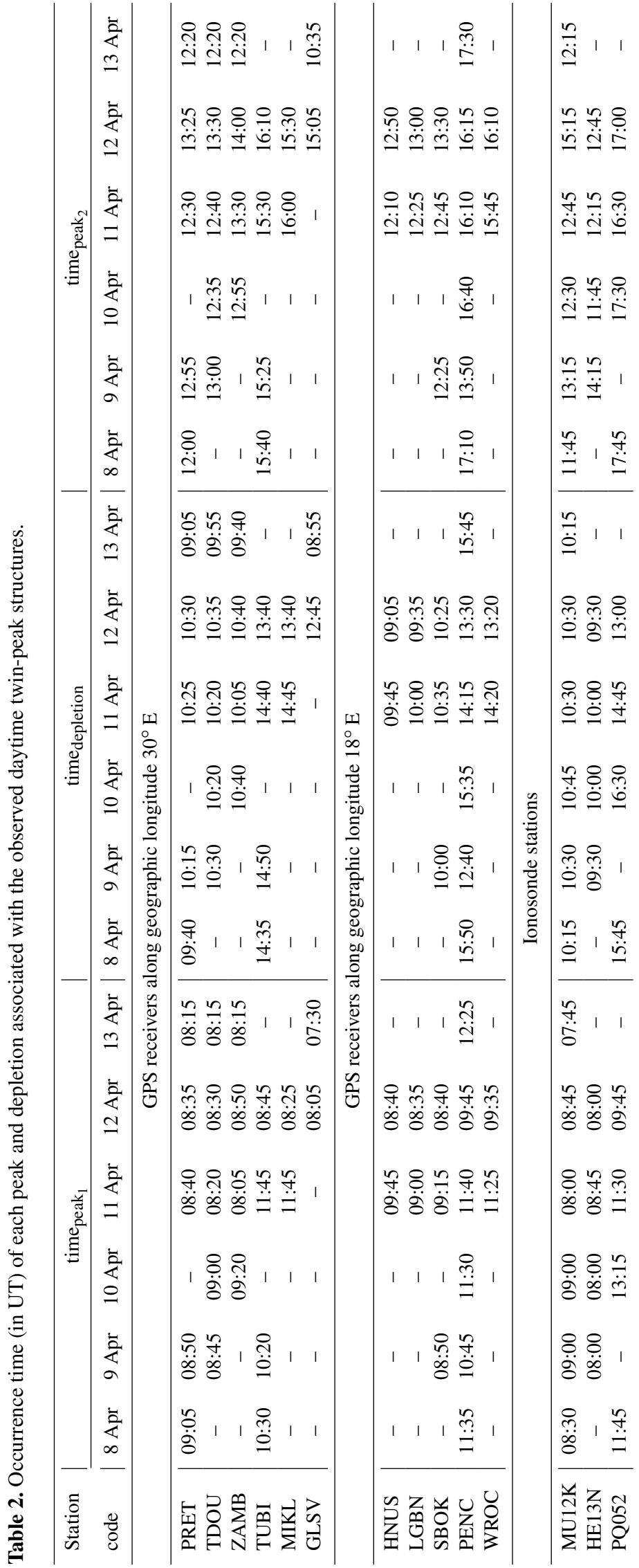

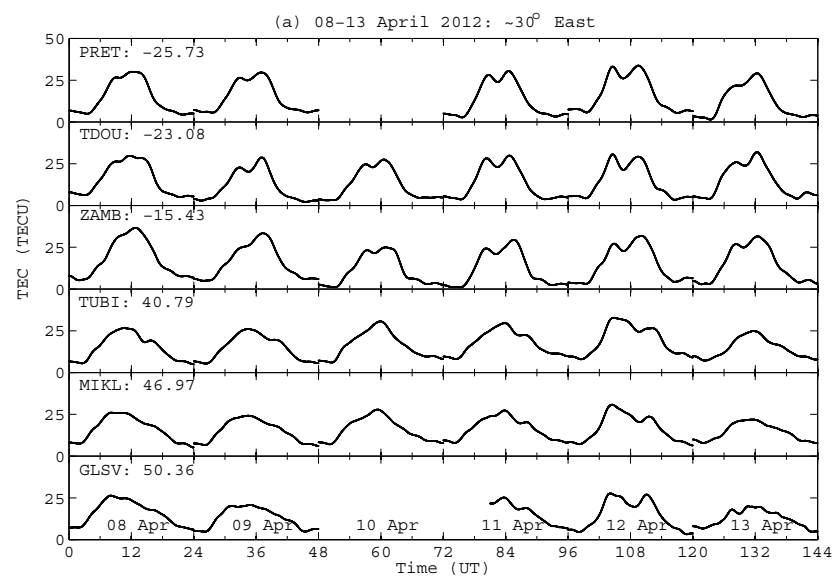

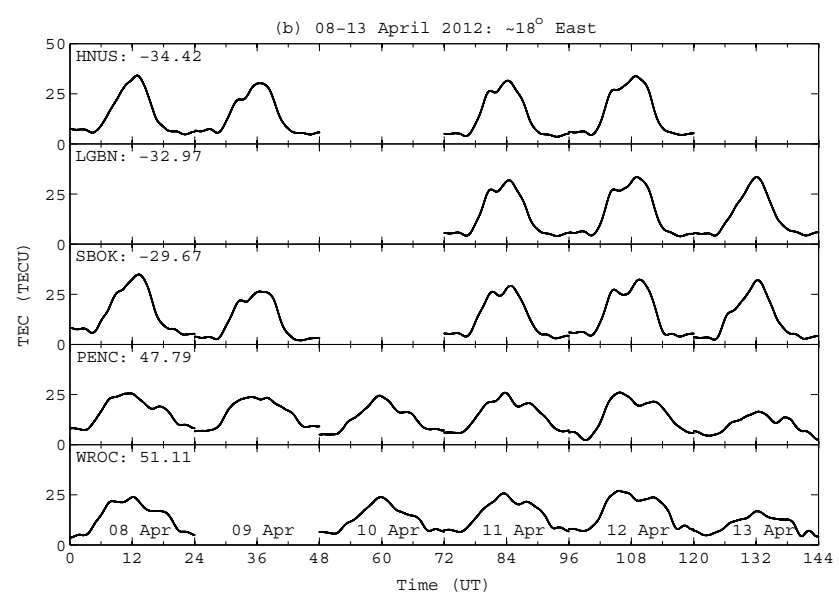

Figure 3. Twin-peak structures observed on 11-13 April 2012 from Northern and Southern Hemisphere GPS stations; station's code and geographic latitudes also included (negative latitudes indicate south, and positive latitudes indicate north).

13 April 2012). The location of these stations is shown in Fig. 1, and their coordinates are also given in Table 1. TEC measurements from these stations are presented in Fig. 4 and show similar bite-out structures to those observed from the middle-latitude stations: MOIU detected these structures on 8, 10 and 11 April; EBBE on 8, 10, 11 and 12 April; and GETA on 8, 9, 11 and 12 April. However the bite-outs appear much later in the EIA region than at middle latitudes. For example on 8 April, the first peaks appeared around 11:05 UT at MOIU and EBBE, and about 10:50 UT at GETA; the depletions were observed around 12:10,11:30 and 11:40 UT at MOIU, EBBE and GETA respectively; and the second peaks were observed around 13:20, 13:40 and 13:45 UT at MOIU, EBBE and GETA respectively. For the same day we deduced that PRET (nearest middle-latitude station to the EIA region on this day) observed similar structures about $2 \mathrm{~h}$ earlier than those at the EIA region; see Table 2. Similarly on 11 and 12 April, the bite-outs at the EIA region appeared $1-4 \mathrm{~h}$ later 


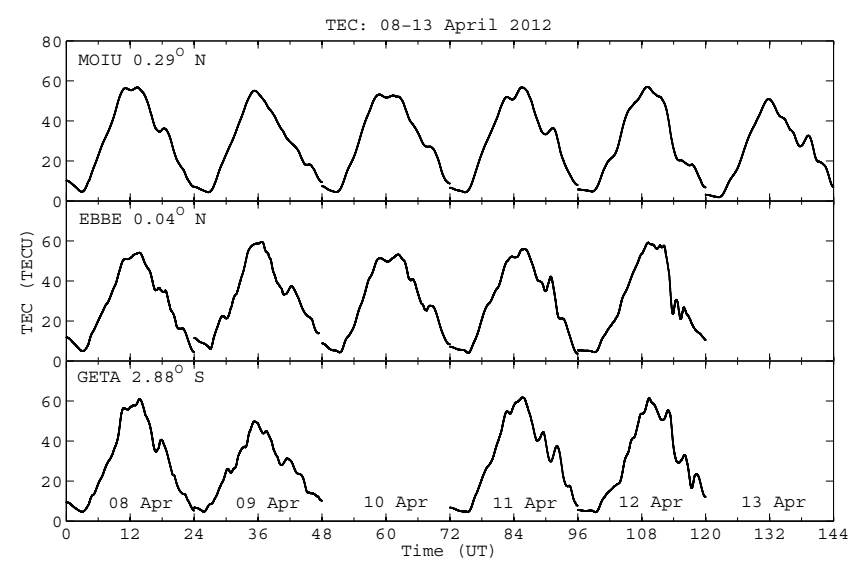

Figure 4. TEC measurements from African low-latitude stations MOIU, EBBE and GETA.

than those at southern middle latitudes. Therefore since the twin-peak structures at the middle latitudes appear not to originate from the EIA region, we can deduce that the EIA did not play a direct role in their generation.

Figure 5 presents diurnal variations of the $N m \mathrm{~F} 2, h m \mathrm{~F} 2$ and vertical component of the equivalent meridional winds (VEW, vertical equivalent winds) over Hermanus (HE13N), Madimbo (MU12K) and Pruhonice (PQ052) ionosonde stations. The MU12K ionosonde is roughly located $90 \mathrm{~km}$ from the TDOU GPS receiver, while the HE13N ionosonde is colocated with the HNUS GPS receiver. In the Northern Hemisphere, there was no ionosonde located with or very closely to any of the GPS receivers, so PQ052 is used instead as it is nearly conjugate to the HE13N ionosonde and is within similar latitudes to GLSV and WROC GPS stations. The positive VEW values correspond to upward vertical equivalent wind drifts, while negative values correspond to downward vertical equivalent wind drifts. The vertical line shows the time of the bite-out, while the dashed line shows the maximum downward vertical drifts of the equivalent winds. Figure 5a shows that, similarly to TEC measurements from HNUS GPS, the HE13N ionosonde also detected the twinpeak structures on 11 and 12 April, within about an hour. While the HNUS GPS did not detect any twin-peak structure on 9 and 10 April, the HE13N ionosonde measurements show that these structures existed on these days as well. Similarly, while the TDOU GPS detected twin-peak structures from 9 to 13 April, the MU12K ionosonde detected them from 8 to 13 April (see Fig. 5d) and within roughly $15 \mathrm{~min}$ of the TDOU GPS having detected them. Figure $5 \mathrm{~g}$ shows that the twin-peak structures were also detected by the PQ052 ionosonde station on almost all the days under investigation (except 9 and 13 April). It is noted that the PQ052 ionosonde (in the Northern Hemisphere) detected the peaks much later than the African ionosonde stations (in the Southern Hemisphere), representing the seasonal variation of twin- peak structures, which was also seen from GPS measurements.

From Figs. 5b, e and $\mathrm{h}$ it is observed that $h m \mathrm{~F} 2$ values decrease prior to the $N m \mathrm{~F} 2$ bite-outs. The time difference between a decrease in $h m \mathrm{~F} 2$ and a decrease in $N m \mathrm{~F} 2$ of the bite-out structures observed over HE13N, MU12K and PQ052 ranges from $45 \mathrm{~min}$ to $1.75 \mathrm{~h}, 45 \mathrm{~min}$ to $1.50 \mathrm{~h}$ and 1.25 to $2.25 \mathrm{~h}$ respectively. These delays are slightly longer than those reported by Saryo et al. (1989), who found a time delay of about $30 \mathrm{~min}$ between the decrease of $h m \mathrm{FF} 2$ and $f o \mathrm{~F} 2$ bite-outs in their study. The decrease of $h m \mathrm{~F} 2$ prior to $N m \mathrm{~F} 2$ bite-outs seems to indicate that the descent of $h m \mathrm{~F} 2$ to altitudes where the dissociative recombination rate of oxygen ion is higher results in plasma depletions observed as biteout structures. This seems to be supported by the fact that the vertical component of the equivalent winds blows downward hours prior to the $h m \mathrm{~F} 2$ decreases (see Figs. $5 \mathrm{c}$, f and i). The maximum downward drift occurs $1.50-2.00 \mathrm{~h}, 2.25-$ $3.50 \mathrm{~h}$ and $1.50-5.50 \mathrm{~h}$ prior to the $h m \mathrm{~F} 2$ decreases in Hermanus, Madimbo and Pruhonice respectively. It is observed that the response time of the $h m \mathrm{~F} 2$ to the downward vertical drifts and the response time of $N m \mathrm{~F} 2$ to the $h m \mathrm{~F} 2$ descent is longer at the European station than at the South African stations.

Figure 6 presents critical frequency and virtual height of the sporadic E layer (i.e. $f o$ Es and h'Es respectively) as determined from ionosondes in Hermanus, Madimbo and Pruhonice. The vertical blue dash-dot lines mark the first and second peak of the twin-peak structure, i.e. the duration of the structure. These results show that, while there is presence of Es layers around the time of twin peaks in $N m \mathrm{~F} 2$ measurements during which the height of the Es layer descends to lower heights, this trend is not consistent for all twin-peak structures noticeable over Madimbo on 12 April. Lynn et al. (2014) also observed two periods of Es layers around the time of the twin peaks; however it is difficult to ascertain if this is the case in this study largely due to data gaps in our Es-layer measurements.

\section{Discussion}

The results presented here show that, although the middlelatitude twin-peak structures travel towards both the Equator and poles, the predominant propagation (about 64\%) is towards the Equator. This result is similar to those reported by Khan et al. (1985) and Saryo et al. (1989). In fact both Khan et al. (1985) and Saryo et al. (1989) attributed the bite-outs they observed to poleward/equatorward neutral winds after ruling out vertical $\mathbf{E} \times \mathbf{B}$ drifts due to the fact that the observing stations were outside of the equatorial anomaly region and the structures were propagating equatorward and thus cannot be originating from enhancement of the equatorial eastward/westward electric field. Both studies reached the conclusion that poleward/equatorward 

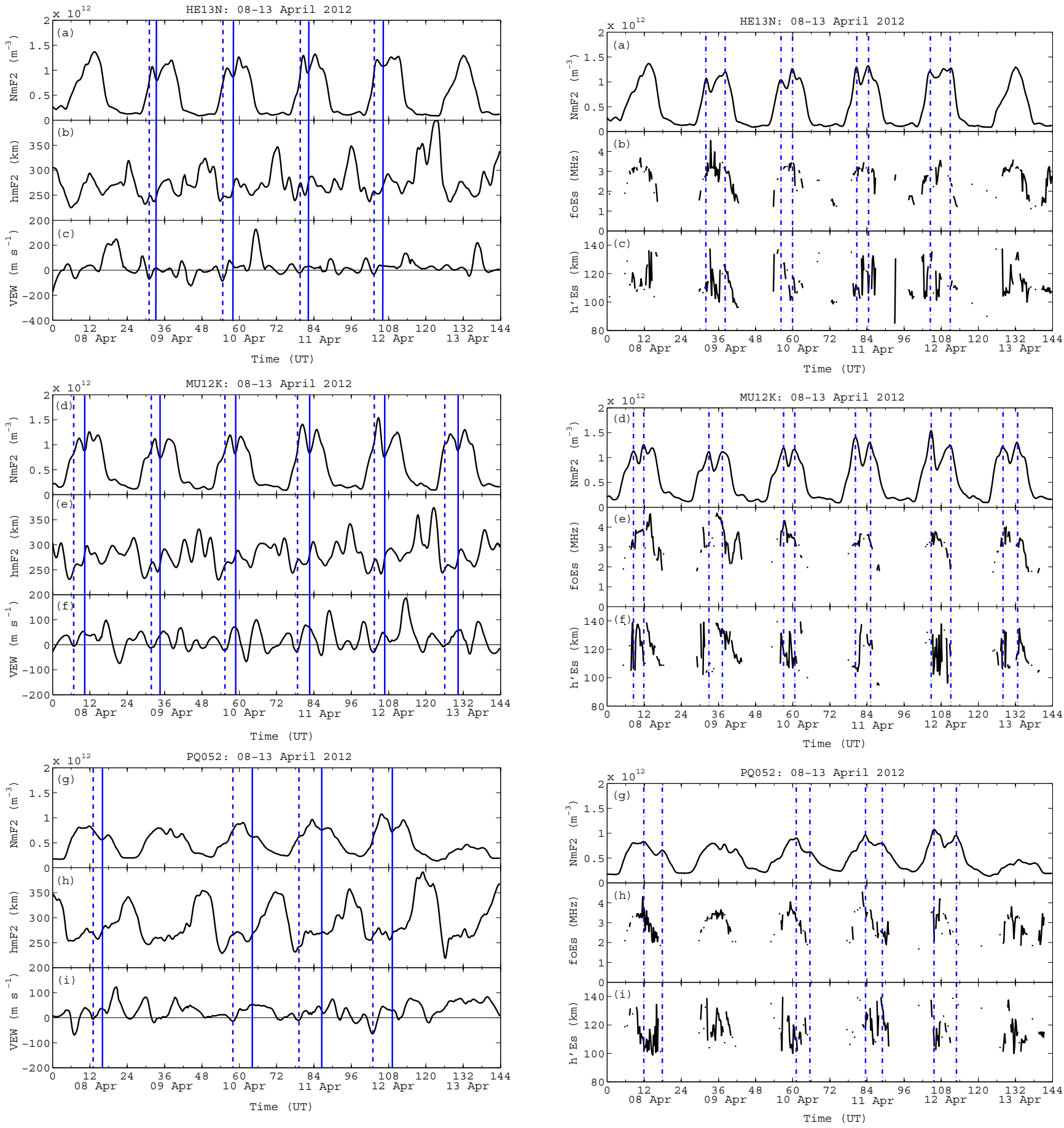

Figure 5. $N m \mathrm{~F} 2$ measurements (a, d and $\mathbf{g}$ ) from Hermanus, Madimbo and Pruhonice ionosonde stations observed on 813 April 2012, showing twin-peak structures, as well as corresponding $h m \mathrm{~F} 2$ measurements in kilometres (b,e and $\mathbf{h})$ and vertical component of equivalent winds in metres per second $(\mathbf{c}, \mathbf{f}$ and $\mathbf{i})$. Vertical blue lines mark depletions in $N m \mathrm{~F} 2$, and vertical dash lines indicate downward wind prior to $\mathrm{NmF} 2$ depletion.

Figure 6. Sporadic E-layer (Es) activity during observations of twin-peak structures as illustrated by its critical frequency, foEs, in (b), (e) and (h) and virtual height, h'Es, in (c), (f) and (i) as measured from Hermanus, Madimbo and Pruhonice ionosondes respectively. The vertical blue dash-dot (-.) lines mark the twin-peak structures observed in $N m \mathrm{~F} 2$ from the same stations (in $\mathbf{a}, \mathbf{d}$ and $\mathbf{g}$ ). 
meridional winds were responsible for the bite-outs because equatorward (poleward) wind pushes the ionised plasma up (down) the magnetic field lines from higher (lower) to lower (higher) latitudes and from a low (high)-loss region into a high (low)-loss region. Under quiet geomagnetic conditions the low-latitude electric field is eastward during the daytime (Hartman and Heelis, 2007) and in the presence of the Earth's magnetic field leads to an upward vertical drift which causes the plasma to ascend to altitudes where recombination is slower, thus resulting in a plasma enhancement. However our results showed that the middle-latitude twin-peak structures occurred prior to those observed in the EIA region. Also since the geomagnetic conditions are quiet, the EIA is not expected to extend to middle-latitude regions. Therefore we deduce that like Khan et al. (1985) and Saryo et al. (1989) the daytime twin-peak structures reported here have no direct link to the EIA.

From the ionosonde data we observed that the $h m \mathrm{~F} 2$ descends to lower altitudes prior to $N m \mathrm{~F} 2$ depletions and that prior to that the vertical drift of the equivalent wind is downward. Theoretical investigations have shown that, when the vertical component of the meridional winds is downward, it moves the F2 plasma into a region of greater loss rate (Kohl et al., 1968; Cho and Yeh, 1970; Miller et al., 1997). From this we deduced that downward drifts of equivalent winds pushed the $h m \mathrm{~F} 2$ to lower altitudes where recombinations are higher, thus leading to $N m \mathrm{~F} 2$ depletions. However of concern is the fact that the response time of $h m \mathrm{~F} 2$ to the equivalent neutral meridional wind effect is several hours, whereas most studies show a response time of less than an hour (Miller et al., 1986; Maruyama et al., 2008). The long response time may be due to errors associated with inaccuracies in deriving the vertical component of the equivalent meridional winds. Muella et al. (2008) point out that if the methods used to derive the neutral winds do not take into account the ionosphere response time, which is the case with the method used here, then discrepancies will arise. Also the uncertainties of neutral parameters derived from neutral atmospheric model, such as neutral densities and temperatures derived from MSIS, have an impact on the discrepancy of the derived vertical component of the equivalent winds. Studies show that even during quiet geomagnetic conditions, these models still fail to reproduce realistic neutral densities (Grossmann et al., 2000; Kurihara et al., 2006). However due to the lack of direct measurements of neutral winds in the regions under study these methods are the best that can be used in an effort to understand the dynamics of the twin-peak structures in relation to neutral winds.

Our results show some Es-layer activity where the lowering of h'Es approximately coincides with the peaks of the twin peaks. These results are similar to those of Lynn et al. (2014), who found a strong presence of descending Es layers in the same period as peaks of the twin-peak structures. They suggested that tidal activity may have an influence on the generation of these structures because descending Es lay- ers reflect wind shear, produced when winds at heights above the Es layer have changed directions, due to migrating tides. This seems to be supported by Haldoupis et al. (2004), Arras et al. (2009) and Fytterer et al. (2014), who have shown that diurnal, semi-diurnal and terdiurnal tides are the main drivers of Es layers by providing large vertical wind gradients, i.e. wind shear. Below $120 \mathrm{~km}$, the downward (upward) Es-layer drift is controlled by westward (eastward) zonal wind, while above this height the Es-layer descent (uplift) is controlled by the poleward (equatorward) meridional winds (Pancheva et al., 2003). Our results show that the Es layer descends from heights above $120 \mathrm{~km}$ during the occurrence of the enhancements of the twin-peak structures. We therefore suggest that the descent of the Es layer observed in this study is linked to meridional wind shear driven by tidal activity. The interaction of these tides with the Es layer will create dynamo electric fields in the $\mathrm{E}$ region which will modulate the ionosphere via $\mathbf{E} \times \mathbf{B}$ vertical drift (Zhang et al, 2010; Forbes et al., 2008). Since during the day the electric field is eastward, it would cause upward vertical drifts which will result in plasma enhancements in the F2 region. This implies that the tidal activity inferred from observations of Es layers at the same time as the enhancements of the twin-peak structures may contribute to the generation of twin-peak structures via the dynamo electric field.

\section{Conclusions}

In this first study of daytime twin-peak structures simultaneously observed over southern Africa and Europe during quiet geomagnetic conditions (8-12 April 2012) and weak storm conditions (13 April 2012 with minimum Dst of $-49 \mathrm{nT}$ ), the following was found:

- The structures appeared at different times of the day with a time of occurrence variation of $1-2 \mathrm{~h}$.

- Twin-peak structures in the form of forenoon/noon biteouts occur in the Southern Hemisphere, whereas secondary afternoon enhancements occur in the Northern Hemisphere.

- Southern Hemisphere structures were observed 1-3 h earlier than the Northern Hemisphere structures, probably an effect of seasonal differences between the two hemispheres.

- From the time delays of the structures between GPS stations along the same longitudes (i.e 18 and $30^{\circ} \mathrm{E}$ ), it was deduced that the structures seem to be propagating mostly equatorward in both hemispheres, except on 11 April when the structures were found to be moving in both directions (i.e. equatorward and poleward).

- The vertical component of equivalent neutral wind derived from ionosonde measurements suggests that the 
bite-out events of the twin-peak structures resulted from downward vertical drifts pushing the plasma down to lower altitudes where the recombination rate is higher, thus causing plasma depletions like those observed in $N m F 2$ and TEC measurements. However the delay of several hours of $h m \mathrm{~F} 2$ response to the vertical component of the equivalent neutral wind is of concern. Detailed study of neutral wind proxy from ionosonde measurements is needed to resolve the ionosphere response time issue.

- NmF2 (and TEC) enhancements are linked to tidal activity, inferred from the presence of descending Es layers, which has been shown to generate upward vertical $\mathbf{E} \times \mathbf{B}$ drifts through the dynamo electric field.

Acknowledgements. This work is based on the research supported in part by the National Research Foundation (NRF) of South Africa for the grant UID-84240. Any opinion, finding, conclusion or recommendation expressed in this material is that of the authors, and the NRF does not accept any liability in this regard. The authors thank South Africa's Chief Directorate: National Geo-spatial Information and the International GNSS Service (IGS) for the GPS data, Dalia Buresova (Institute of Atmospheric Physics, Academy of Sciences of the Czech Republic) for the Pruhonice ionosonde data and Libo Liu (Institute of Geology and Geophysics, Chinese Academy of Sciences) for his assistance with the equivalent meridional wind method. We are grateful to the referees and editor for the constructive comments.

The topical editor, H. Kil, thanks two anonymous referees for help in evaluating this paper.

\section{References}

Amayenc, P.: Tidal oscillations of the meridional neutral wind at midlatitudes, Radio Sci., 9, 281-293, 1974.

Arras, C., Jacobi, C., and Wickert, J.: Semidiurnal tidal signature in sporadic E occurrence rates derived from GPS radio occultation measurements at higher midlatitudes, Ann. Geophys., 27, 25552563, doi:10.5194/angeo-27-2555-2009, 2009.

Bilitza, D., Altadill, D., Zhang, Y., Mertens, C., Truhlik, V., Richards, P., McKinnell, L., and Reinisch, B.: The International Reference Ionosphere 2012 - a model of international collaboration, J. Space Weather Space Clim., 4, A07, doi:10.1051/swsc/2014004, 2014.

Burrage, M. D., Wu, D. L., Skinner, W. R., Ortland, D. A., and Hays, P. B.: Latitudinal and seasonal dependence of the semidiurnal tide observed by the high-resolution Doppler imager, J. Geophys. Res., 100, 11313-11321, 1995.

Cho, H. R. and Yeh, K. C.: Neutral winds and the behavior of the ionospheric $\mathrm{F}_{2}$ region, Radio Sci., 5, 881-894, 1970.

Dyson, P. L., Davies, T. P., Parkinson, M. L., Rees, A. J., Richards, P. G., and Fairchild, C. E.: Thermospheric neutral winds at southern mid-latitudes: A comparison of optical and ionosonde $h_{m} F_{2}$ methods, J. Geophys. Res., 102, 27189-27196, 1997.
Forbes, J. M., Zhang, X., Palo, S., Russell, J., Mertens, C. J., and Mlynczak, M.: Tidal variability in the ionospheric dynamo region, J. Geophys. Res., 113, A02310, doi:10.1029/2007JA012737, 2008.

Fytterer, T., Arras, C., Hofmann, P., and Jacobi, C.: Global distribution of the migrating terdiurnal tide seen in sporadic E occurrence frequencies obtained from GPS radio occultations, Earth Planets Space, 66, 79, doi:10.1186/1880-5981-66-79, 2014.

Grossmann, K. U., Kaufmann, M., and Gerstner, E.: A global measurement of lower thermosphere atomic oxygen densities, Geophys. Res. Lett., 27, 1387-1390, 2000.

Haldoupis, C., Pancheva, D., and Mitchell, N. J.: A study of tidal and planetary wave periodicities present in midlatitude sporadic E layers, J. Geophys. Res., 109, A02302, doi:10.1029/2003JA010253, 2004.

Haldoupis, C., Meek, C., Christakis, N., and Pancheva, D.: Ionogram height-time intensity observations of descending sporadic E layers at mid-latitude, J. Atmos. Sol. Terr. Phys., 68, 539-557, 2006.

Hartman, W. A. and Heelis, R. A.: Longitudinal variations in the equatorial vertical drift in the topside ionosphere, J. Geophys. Res., 112, A03305, doi:10.1029/2006JA011773, 2007.

Hedin, A. E.: Extension of the MSIS Thermosphere Model into the middle and lower atmosphere, J. Geophys. Res., 96, 1159-1172, doi:10.1029/90JA02125, 1991.

Hibbins, R. E., Freeman, M. P., Milan, S. E., and Ruohoniemi, J. M.: Winds and tides in the mid-latitude Southern Hemisphere upper mesosphere recorded with the Falkland Islands SuperDARN radar, Ann. Geophys., 29, 1985-1996, doi:10.5194/angeo-291985-2011, 2011.

Huang, Y.-N. and Jeng, B.-S.: On the forenoon bite-out in the critical frequency of the F2-layer, J. Atmos. Terr. Phys., 40, 581-584, 1978.

Jones, M., Jr, Forbes, J. M., Hagan, M. E., Maute, A., Impacts of vertically propagating tides on the mean state of the ionospherethermosphere system, J. Geophys. Res.-Space, 119, 2197-2213, doi:10.1002/2013JA019744, 2014.

Katamzi, Z. T., Smith, N. D., Mitchell, C. N., and Spalla, P.: Analysis of diurnal double maxima observed above Italy during 1975-1991, J. Atmos. Sol. Terr. Phys., 89, 67-75, doi:10.1016/j.jastp.2012.08.001, 2012.

Khan, Z. M., Ara, H., Iqbal, S., and Nasir, M.: On the cause of forenoon \& post-noon bite-outs in $\mathrm{f}_{o} \mathrm{~F}_{2}$, J. Atmos. Terr. Phys., 47, 719-724, 1985.

Kohl, H., King, J. W., and Eccles, D.: Some effects of neutral air winds on the ionospheric F-layer, J. Atmos. Terr. Phys., 30, 1733-1744, 1968.

Kurihara, J., Abe, T., Oyama, K., Griffin, E., Kosch, M., Aruliah, A., Kauristie, K., Ogawa, Y., Komada, S., and Iwagami, N.: Observations of the lower thermospheric neutral temperature and density in the DELTA campaign, Earth Planets Space, 58, 1123 1130, 2006.

Liu, L., Luan, X., Wan, W., Lei., J., and Ning, B.: Solar activity variations of equivalent winds derived from global ionosonde data, $\mathrm{J}$. Geophys. Res., 109, A12305, doi:10.1029/2004JA010574, 2004.

Liu, L., Luan, X., Wan, W., Ning, B., and Lei, J.: A new approach to the derivation of dynamic information from ionosonde measurements, Ann. Geophys., 21, 2185-2191, doi:10.5194/angeo21-2185-2003, 2003. 
Lynn, K. J. W., Gardiner-Garden, R. S., and Heitmann, A.: The spatial and temporal structure of twin peaks and midday biteout in $\mathrm{f}_{o} \mathrm{~F} 2$ (with associated height changes) in the Australian and South Pacific low midlatitude ionosphere, J. Geophys. Res.Space, 119, 10294-10304, doi:10.1002/2014JA020617, 2014.

Maruyama, T., Saito, S., Kawamura, M., and Nozaki, K.: Thermospheric meridional winds as deduced from ionosonde chain at low and equatorial latitudes and their connection with midnight temperature maxumum, J. Geophys. Res., 113, A09316, doi:10.1029/2008JA013031, 2008.

Miller, K. L., Torr, D. G., and Richards, P. G.: Meridional winds in the thermosphere derived from measurements of $F_{2}$ layer height, J. Geophys. Res., 91, 4531-4535, 1986.

Miller, K. L., Lemon, M., and Richards, P. G.: A meridional wind climatology from a fast model for the derivation of meridional winds from the height of the ionosphereic F2 region, J. Atmos. Sol. Terr. Phys., 59, 1805-1822, 1997.

Muella, M. T. A. H., Fagundes, P. R., Bittencourt, J. A., Sahai, Y., Lima, W. L. C., Becker-Guedes, F., Pillat, V. G., Nighttime thermospheric meridional neutral winds inferred from ionospheric $h^{\prime} F$ and $h p F 2$ data, Adv. Space Res., 41, 599-610, doi:10.1016/j.asr.2007.09.032, 2008.

Oberheide, J., Shiokawa, K., Gurubaran, S., Ward, W. E., Fujiwara, H., Kosch, M. J., Makela, J. J., and Takahashi, H.: The geospace response to variable inputs from the lower atmosphere: a review of the progress made by Task Group 4 of CAWSES-II, Progress in Earth and Planetary Science, 2, 2, doi:10.1186/s40645-0140031-4, 2015.
Pancheva, D., Haldoupis, C., Meek, C. E., Manson, A. H., and Mitchell, N. J.: Evidence of a role of modulated atmospheric tides in the dependence of sporadic $\mathrm{E}$ layes on planetary waves, J. Geophys. Res., 108, 1176, doi:10.1029/2002JA009788, 2003.

Pi, X., Mendillo, M., Fox, M. W., and Anderson, D. N.: Diurnal double maxima patterns in the $\mathrm{F}$ region ionosphere: substorm-related analysis aspects, J. Geophys. Res., 98, 13677-13691, 1993.

Saryo, T., Takeda, M., Araki, T., Sato, T., Tsuda, T., Fukao, S., and Kato, S.: A midday bite-out even of the F2-layer observed by MU radar, J. Goemag. Geoelectr., 41, 727-734, 1989.

Seemala, G. K. and Valladares, C. E.: Statistics of total electron content depletions observed over the South American continent for the year 2008, Radio Sci., 46, RS5019, doi:10.1029/2011RS004722, 2011.

Whitehead, J. D.: The formation of the sporadic-E layer in the temperature zones, J. Atmos. Terr. Phys., 20, 49-58, 1961.

Xiong, C., Zhou, Y.-L., Lühr, H., and Ma, S.-Y.: Tidal signatures of the thermospheric mass density and zonal wind at midlatitude: CHAMP and GRACE observations, Ann. Geophys., 33, 185196, doi:10.5194/angeo-33-185-2015, 2015.

Zhang, Y., England, S., and Paxton, L. J.: Thermospheric composition variations due to nonmigrating tides and their effect on ionosphere, Geophys. Res. Lett., 37, L17103, doi:10.1029/2010GL044313, 2010. 